\title{
Presence of P210bcrabl Is Associated with Decreased Expression of a Beta Chemokine C10 Gene in a P210bcrabl-Positive Myeloid Leukemia Cell Line
}

\author{
Cynthia M. Lane, ${ }^{1,2}$ Xiang-Yang Guo, ${ }^{3}$ Laurel H. Macaluso, ${ }^{1}$ \\ Katherine C. Yung, ${ }^{2}$ and Albert B. Deisseroth ${ }^{3}$ \\ ${ }^{1}$ The University of Texas M.D. Anderson Cancer Center, Houston, \\ Texas, U.S.A. \\ ${ }^{2}$ Baylor School of Medicine and Methodist Hospital, Texas Medical \\ Center Complex, Houston, Texas, U.S.A. \\ ${ }^{3}$ Yale University School of Medicine, New Haven, Connecticut, U.S.A. \\ Accepted November 10, 1998.
}

\begin{abstract}
Background: Chronic myelogenous leukemia $(\mathrm{CML})$ is thought to start with the acquisition of the $t(9 ; 22)$ chromosomal translocation that codes for the P210bcrabl tyrosine-specific protein kinase. The CML cells exhibit anchorage-independent cell growth and genetic instability. After the initial phase, the cells acquire the phenotype of growth factor-independent growth. After the chronic phase, the disease evolves into the accelerated and blastic phases through the process of sequential random mutation.

Materials and Methods: To identify some of the genetic changes that contribute to the phenotype of blastic and accelerated phase cells, we used differential display PCR to compare levels of cDNA reverse transcripts of mRNA in 32Dcl 3 cells and 32Dcl 3 cells that were stably transfected with a bcrabl cDNA plasmid in a constitutively expressed transcription unit. These cells were des-
\end{abstract}

ignated 32Dcl3P210bcrabl. For these studies, we used the 32D myeloid leukemia cell line, which depends on IL-3 for growth.

Results: Following introduction of the bcr-abl cDNA through transfection, the cell line became growth factor independent, mimicking the change in phenotype that occurs during the later phases of CML. These differential display screening assays detected altered levels of transcripts for 28 genes. Of interest to the biology of growth factor-independent growth in the bcrabl-positive $32 \mathrm{D}$ cells was the fact that the C10 $\beta$ chemokine gene was expressed at higher levels in the 32Dc13 cells than in the 32Dcl 3P2 10bcrabl cells.

Conclusions: These studies show that a $\mathrm{C} 10 \beta$ chemokine gene was expressed at different levels with or without P210bcrabl.

\section{Introduction}

The Philadelphia chromosome translocation, which generates the P210bcrabl tyrosine-specific protein kinase, results from a balanced translo-

Address correspondence and reprint requests to: Dr. Albert Deisseroth, Medical Oncology Section and Gene Therapy Program, Yale University School of Medicine, New Haven, CT 06520-8032, U.S.A. Phone: 203-737-5608; Fax: 203-

737-5698; E-mail: albert.deisseroth@yale.edu cation between chromosomes 9 (abl) and 22 (bcr) $(1,2)$. This genetic marker is present in the leukemia cells of more than $95 \%$ of all patients with chronic myelogenous leukemia (CML). Although the bcr-abl is associated with the presence of anchorage-independent growth and genetic instability, the full expression of the leukemia phenotype (e.g., growth factor-independent growth) and the progression of the dis- 
ease to its ultimate blastic transformation require additional genetic changes. Genetic changes that have been identified in blast crisis CML at the chromosomal level include trisomy 8 , isochromosome 17, and changes in $p 53(3,4)$.

The cabl protein kinase, which is the normal cellular homologue to P210bcrabl, is a highly regulated, cycle-dependent, nonreceptor-associated tyrosine-specific protein kinase, which is predominantly but not exclusively nuclear in location. In contrast, the P210bcrabl tyrosine-specific protein kinase (5) is active in a more unregulated fashion in the cytoplasm. This has led to the proposal that the presence of the P210bcrabl initiates genetic changes that generate changes in gene expression, as shown previously in animal models (6). To test this hypothesis, we used differential display polymerase chain reaction (DDPCR) to test if the transcript levels of genes were altered as a result of stable transfection of the bcrabl cDNA, into the mouse myeloid cell line 32Dc13. We also attempted to identify changes in the levels of individual transcripts that are associated with bcrabl cDNA.

The differential display technique, developed by Liang and Pardee (7) in 1992, has been used to identify the potential roles of many genes, such as the $\alpha 6$ integrin as a potential tumor suppressor (8), and the ras-activated gene $M-b$ (9), to cite a few $(10-12)$. The purpose of differential display is to amplify all of the expressed messages in a cell or tissue under specific conditions and compare the results of these assays with the results obtained with the same cells under a different set of conditions. In the work reported here, cDNA was prepared with single base-anchored poly $\mathrm{T}$ oligomers. The cDNA generated from the total RNA of 32D cells before and after transfection of the bcrabl cDNA was amplified with the corresponding poly-T-oligomer and a random decamer. This was repeated with eight random decamers in an attempt to amplify all expressed messages. PCR products were separated on denaturing $6 \%$ polyacrylamide gels. Differentially expressed products were cut out and reamplified to confirm differential expression. Since PCR is only semiquantitative, all experiments were repeated three times, and fragments chosen for sequencing were those showing major differences in the 32D cells before and after introduction of the bcrabl cDNA.

Preliminary data indicate that the transcript levels of several genes are differentially regulated in 32Dcl3P210bcrabl when compared with untransfected cells. We have identified the genes coding for these transcripts, including transcripts that are similar to the C10-like $\beta$ chemokine, which was expressed at higher levels in 32D cells than in 32Dcl 3P2 10 bcrabl cells. The implications of these studies are discussed here.

\section{Materials and Methods}

Cells

Stock cultures of 32Dcl 3 were a generous gift of Dr. Joel Greenberger, Department of Radiation Oncology, University of Pittsburgh, Pittsburgh, PA. Cells were grown in Iscoves modified Eagles medium (IMEM; GIBCO/BRL) in suspension culture. Media were supplemented with $10 \%$ heat-inactivated fetal bovine serum (FBS) and $10 \%$ WEHI- 3 conditioned media; WEHI-3 cells secrete interleukin-3 (IL-3).

\section{Construction of P210bcrabl Cell Line}

A human bcr-abl cDNA was subcloned into a pcDNA3 expression vector (Invitrogen), which also contained a Neo gene. Following electroporation of this vector into 32D cells, the cells were allowed to recover in complete DMEM medium with 10\% WEHI-3 medium, supplemented with IL-3, for 2 days at $37^{\circ} \mathrm{C}$. Total RNA and protein extracts were prepared from the 32D cells transfected with pcDNA3 vector alone, and 32D cells transfected with the pcDNA3 bcr-abl vector (32Dc13P210bcrabl). The transfected cells were then plated in $0.9 \%$ methylcellulose supplemented with $30 \%$ FBS (Stem Cell Technology, Inc.) and selected with $0.75 \mathrm{mg} / \mathrm{ml} \mathrm{G418}$. No IL-3 was present in the growth medium at this point or thereafter. After 14 days, no colonies were found in control plates in which the pcDNA vector alone (Neo-positive, bcr-abl-negative) was transfected into the 32D cells, whereas colonies were detected in cultures of the 32Dcl3P210bcrabl. Individual colonies growing in the plates inoculated with cells transfected with the pcDNA-P210bcrabl (Neo- and bcr-ablpositive) vector were picked and grown in complete Dulbeccos modified Eagle medium (DMEM) medium. Total RNA extracts were prepared from the 32Dcl3P210bcrabl cells.

\section{RNA Isolation and Differential Display}

Total RNA was isolated from fresh 32D cells and 32Dc13P210bcrabl with RNAzol (Tel-Test, Friendswood, TX) according to the protocol sup- 
plied by the manufacturer. To remove any possible DNA contaminants, RNA was treated with RNase-free DNase (Boehringer-Mannheim) and reprecipitated.

Differential display was carried out with the GenHunter (Memphis, TN) kit using the protocol supplied by the manufacturer with the following modifications: $400 \mathrm{ng}$ of RNA was used instead of $200 \mathrm{ng}$; the dNTP concentration was increased from $2 \mu \mathrm{M}$ to $25 \mu \mathrm{M}$ final concentration; and expanded PCR enzyme (Boehringer-Mannheim, Indianopolis, IN) was used in place of Taq polymerase at a volume of $0.3 \mu \mathrm{M}$ instead of $0.2 \mu \mathrm{M}$. The PCR cycles were carried out on a Perkin Elmer DNA thermal cycler under the following conditions: $92^{\circ} \mathrm{C}$ for $30 \mathrm{sec}, 40^{\circ} \mathrm{C}$ for $2 \mathrm{~min}, 68^{\circ} \mathrm{C}$ for $30 \mathrm{sec}, 40$ cycles followed by 1 cycle at $68^{\circ} \mathrm{C}$ for $5 \mathrm{~min}$. PCR products were separated on $6 \%$ denaturing polyacrylamide gels, vacuum dried, marked for orientation, and exposed to hyperfilm (Amersham, Arlington Heights, IL) overnight. This procedure was repeated at least three times for all primer combinations. Reproducible differences were reamplified according to the GenHunter protocol.

Reamplified bands were cloned with the PCR-Trap cloning system (GenHunter) according to the manufacturer's protocol and sent for automated sequencing (UT MD Anderson sequencing facility). GenBank was searched for the sequences thus generated using GCG software.

\section{PCR Reactions to Confirm Results}

Primers were designed upstream to the site of the clone product obtained from differential display. Primer sequences were as follows: 5'-CACTGCCCTCCTGGAAATA and 5'-CAGCGTGGTTAAATGGTCTTG for C10-like $\beta$ chemokine. CDNA was amplified by PCR using AmpliTaq polymerase (Perkin Elmer) according to the manufacturer's instructions with a $1 \mu \mathrm{M}$ final concentration for each primer. This reaction was carried out in a DNA thermocycler (Perkin Elmer) under the following cycle conditions: $94^{\circ} \mathrm{C}$ for $4 \mathrm{~min}, 1$ cycle; $94^{\circ} \mathrm{C}$ for $1 \mathrm{~min}, 52^{\circ} \mathrm{C}$ for $1 \mathrm{~min}$, and $72^{\circ} \mathrm{C}$ for $1 \mathrm{~min}, 40$ cycles; and $72^{\circ} \mathrm{C}$ for $7 \mathrm{~min}, 1$ cycle. For $\mathrm{C} 10$-like $\beta$ chemokine, a $58^{\circ} \mathrm{C}$ annealing temperature was used. Samples were separated on a $2 \%$ agarose gel and stained with ethidium bromide. The molecular weight marker used was a $100 \mathrm{bp}$ (Promega) PCR product ladder. Each band in the marker set occurred at $100 \mathrm{bp}$ increments with the darkest highest band being at 500 bp.

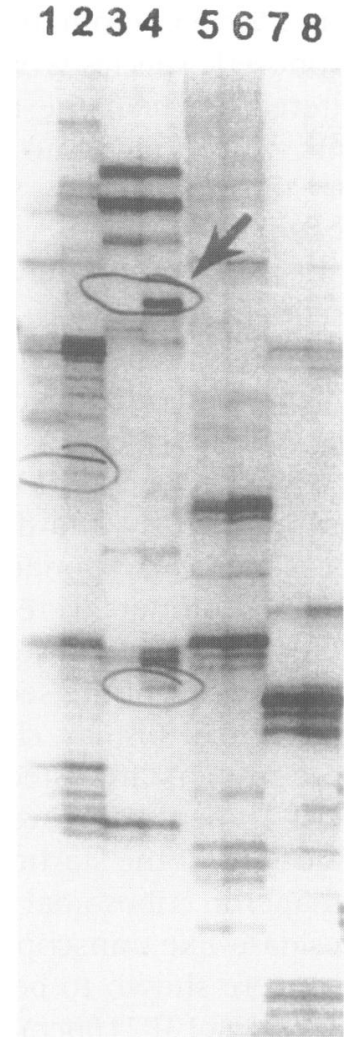

Fig. 1. Example of typical differential display results. Odd-numbered lanes represent untransfected 32D cell DD-PCR products; even-numbered lanes represent DD-PCR products from 32D cells transfected with bcrabl. Each set of two lanes used the same primer set. Circled bands show minor differences. The arrow gives an example of a band that was excised and reamplified.

\section{Results}

Our early experiments with PCR generally produced inconsistent results. Thus to achieve consistent results with RNA species from the 32Dcl 3 cell lines before and after bcr-abl cDNA transfection, we carried out experiments in which the amounts of input RNA, dNTPs, buffer, and Taq enzyme were systemically altered so as to identify optimal conditions for the reactions. The protocol used in these experiments was adopted only after prior optimization as described in Materials and Methods. Eighty 5' primers were used in an attempt to amplify all expressed messages, and all experiments were repeated at least three times. The result of a representative experiment is presented in Figure 1. Bands found to be differentially expressed in the 32D cells at higher or lower levels than that found in the 32Dcl 3P210bcrabl cells were excised, purified, and reamplified. The average size of these prod- 
ucts was about $250 \mathrm{bp}$. From this screen, 28 distinct electrophoretic species were found to be consistently altered between the two cell lines. These fragments were cloned into the PCR-Trap cloning vector and sequenced. Several genes that corresponded to the open reading frames contained in these fragments have been identified from sequence analysis. Two of the clones, whose expression was decreased in the 32Dcl3P210bcrabl, were identified as belonging to the $\mathrm{C} 10 \beta$ chemokine which was overexpressed in 32D cells as compared to 32Dcl3P210bcrabl.

To confirm the identity and differential expression of the genes corresponding to known open reading frames, primers were designed that were homologous to regions present in the candidate genes and were $5^{\prime}$ of the sequences identified in the differential display clones. The sequences of these primers are listed in Materials and Methods. As shown in Figure 2, when we used 10 -fold dilutions of the starting CDNA TCPl-containing chaperon, ribosomal protein L37a, and a $\beta$-galactosidase-like transcript, the levels of all the products were shown to be reproducibly increased in the 32Dcl3P210bcrabl cells, compared with the GADPH loading control. The expression of the $\mathrm{C} 10 \beta$ chemokine gene was higher in the 32Dcl 3 untransfected cells than in the 32Dcl3P210bcrabl transfected cells (see Fig. 3). As a control for DNA contamination, no reverse transcriptase was added to GADPH controls for both 32D and 32Dcl 3P210bcrabl. Under these conditions, no products were seen (see Fig. 2). In contrast, the results obtained with primers for histone $\mathrm{Hl}(0)$ did not give consistent results for increased or decreased expression (Fig. 4). This may be because the difference in levels of $\mathrm{Hl}(0)$ transcripts in the two cell lines is too small to be detected by reverse transcriptase PCR.

\section{Discussion}

The P210bcrabl protein product of the Philadelphia chromosome translocation has been shown to be associated with the phosphorylation of postreceptor kinases (JAKl), cytoplasmic precursors of nuclear transcriptional regulatory proteins (STAT1, STAT3, and STAT5), structural and cytoskeletal proteins involved in intercellular cytoadhesion molecules (paxillin, F-actin), Ras adaptor proteins (CRKL and GRB-2), PI 3-kinase, and JNK kinase. P210bcrabl has been shown to activate the RAS RAP, MAP kinase kinase, the
M123456789101112

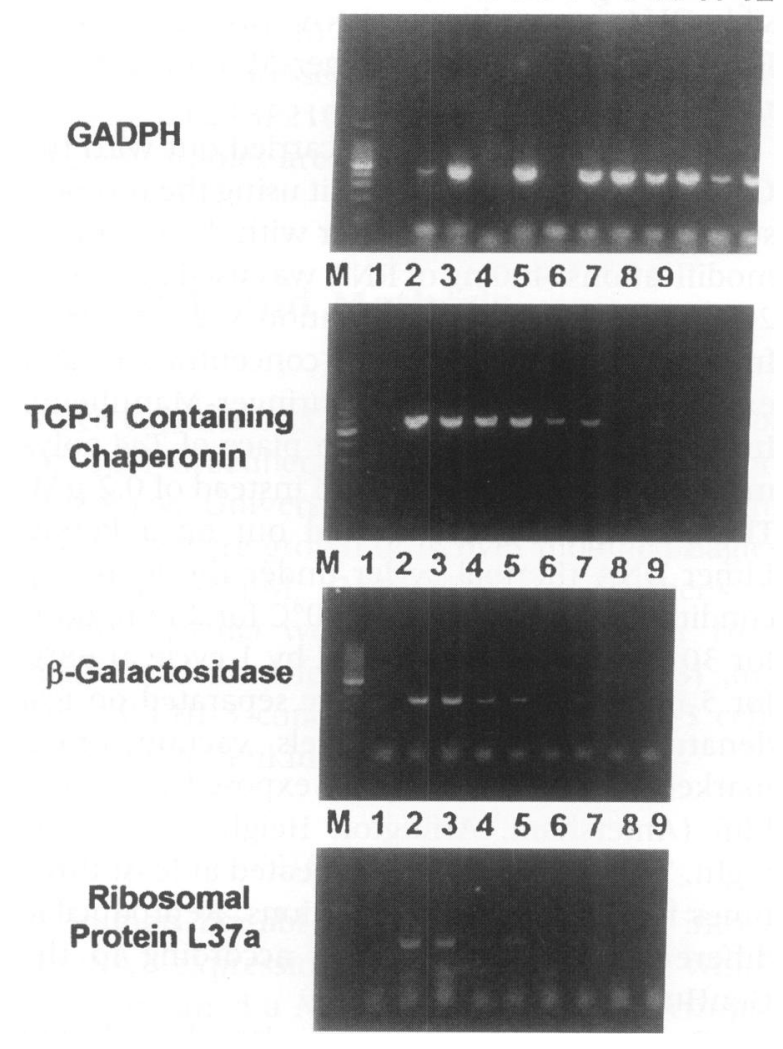

Fig. 2. TCP-1-containing chaperonin, $\beta$-galactosidase, and ribosomal protein L37a gene expression is increased in 32D cells transfected with bcrabl. Lane $M$ is the 100 bp PCR product ladder. The darkest band is 500 bp. GADPH: lane 1, blank; lane 2, water control (there was slight leakage from the adjacent well); lane 3, $100 \mathrm{ng}$ 32D RNA with reverse transcriptase (RT); lane 4, $100 \mathrm{ng}$ 32D RNA without RT; lane 5, $100 \mathrm{ng}$ of 32DC13P210bcrabl RNA; lane 6, 100 ng of RNA from 32Dcl 3P2 $10 \mathrm{bcrabl}$ without addition of RT; lanes 7, 8, $10 \mathrm{ng}$ 32D and 32Dcl3P210bcrabl; lanes $9,10,1 \mathrm{ng}$ 32D and 32Dcl3P210bcrabl; lanes 11, $12,100 \mathrm{pg}$ of 32Dcl3 and 32Dcl3P210bcrabl with RT. Figures labeled TCP-1 containing chaperonin, $\beta$-galactosidase, and ribosomal protein L37a were amplified with primers corresponding to indicated genes in the presence of RT with the following RNA as starting material: lane 1 , water control; lanes 2, 3, $100 \mathrm{ng}$ of 32Dcl3 and 32D cl3P210bcralbl; lanes 4, 5, $10 \mathrm{ng} 32 \mathrm{Dcl} 3$ and 32Dcl 3P2 $10 \mathrm{bcrabl}$; lanes 6, 7, $1 \mathrm{ng}$ 32Dcl3 and 32Dcl3P210bcrabl; lanes 8, 9, 100 pg 32Dcl 3 and 32Dcl3P210bcrabl.

MAP kinase pathway, the RAS/JUN/JNK kinase pathway, and the PI 3-kinase pathway. These changes are associated with the phenotype of growth factor- and anchorage-independent growth. Although the direct relationship between the phosphorylation of these substrates by the P210bcrabl protein and the leukemic pheno- 


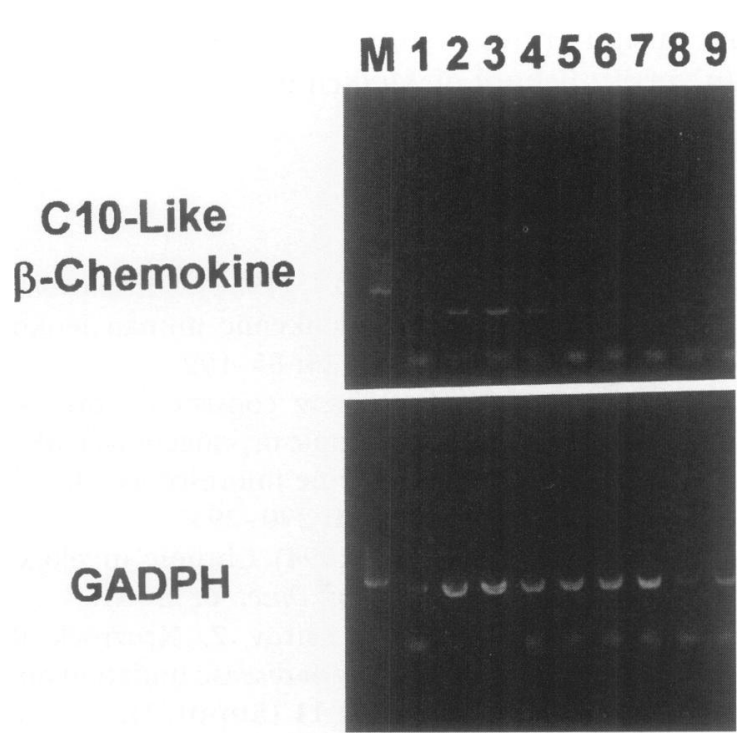

Fig. 3. The $\beta$ chemokine $\mathrm{ClO}$ is overexpressed in $32 \mathrm{Dc} 13$ cells compared with 32Dc13P210bcrabl cells. The top panel shows cDNA amplified with $\beta$ chemokine C10 primers; the bottom panel shows the same starting material as above amplified with GADPH primers as a loading control. Gels were loaded as follows: lane 1, water control; lanes 2, 3, $100 \mathrm{ng} 32 \mathrm{Dcl} 3$ and 32Dcl3P210bcrabl; lanes 4, 5, $10 \mathrm{ng} 32 \mathrm{Dcl} 3$ and 32Dcl 3P2 l obcrabl RNA; lanes 6, 7, 1 ng 32Dcl 3 and 32Dcl3P210bcrabl; lanes 8, 9, $100 \mathrm{pg} 32 \mathrm{Dcl} 3$ and 32Dcl3P210bcrabl RNA. Note there is a faint band in lane 6 but no band in lane 7 for $\beta$ chemokine $\mathrm{C} 10$.

types, such as growth factor-independent growth, is not yet established, it is possible that altered levels of the expression of several growth-regulatory genes and induction of cytoadhesion molecules would be a consequence of this altered phosphorylation. Perhaps the most interesting example of this is the increased expression of the $\beta$ chemokine $\mathrm{C} 10$ in the $32 \mathrm{D}$ cells compared with that in the 32Dcl3P210bcrabl cells.

The $\beta$ chemokine C10, RANTES, and MIP-1 $\alpha$ all belong to the C-C family of $\beta$ chemokines (13-15). Lipopolysaccharide (LPS) induces MIP- $1 \alpha$ but not $\beta$ chemokine C10 $(14,15)$. IL- 4 induces $\beta$ chemokine C10 but not MIP-1 $\alpha$ $(14,15)$. IL-1 and granulocyte-macrophage colony-stimulating factor (GM-CSF) induce significant increases in $\beta$ chemokine $\mathrm{Cl0}$, but not in MIP- $1 \alpha(14,15)$. While MIP- $1 \alpha$ may enhance the inflammatory response and cellular proliferation, $\beta$ chemokine $\mathrm{Cl} 0$ has recently been shown to be elevated in late-stage myeloid hematopoietic progenitor cells as well as in 32D cells and may

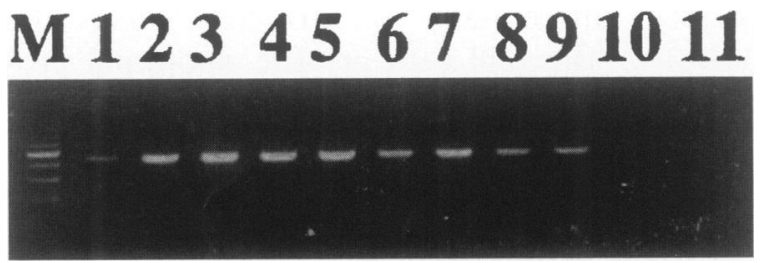

Fig. 4. Histone $\mathrm{Hl}(0)$ is equally expressed in 32Dc13 cells compared with 32Dc13P210bcrabl. cDNA was amplified with primers corresponding to histone $\mathrm{Hl}(0)$. Gels were loaded as follows: lane 1, water control; lanes 2, 3, $100 \mathrm{ng} 32 \mathrm{Dcl} 3$ and 32Dcl3P210bcrabl RNA; lanes 4, 5, $10 \mathrm{ng}$ 32Dcl3 and 32Dcl3P210bcrabl RNA; lanes 6, 7, $1 \mathrm{ng}$ 32Dcl 3 and 32Dcl 3P210bcrabl RNA; lanes 8, 9, 100 pg of 32Dcl3 and 32Dcl3P210bcrabl RNA; and lanes $10,11,10 \mathrm{pg}$ 32Dcl3 and 32Dcl3P210bcrabl RNA. Note that there is no significant difference between the sets of samples.

antagonize proliferation in these cells and suppress the inflammatory and proliferative response in lymphoid cells $(14,15)$.

MIP- $1 \alpha$ is a molecule that is secreted by stromal cells exposed to interferon. This molecule acts on normal myeloid precursor cells to reduce the proliferation of these cells. CML cells do not bind to stromal cells (16-18) and have been shown not to be sensitive to the action of MIP$1 \alpha$, presumably because of the inability of these cells to bind to the stromal cells that release the MIP- $1 \alpha$ locally in the vicinity of the stem cells (19).

$\beta$ chemokine $\mathrm{C} 10$, in contrast, is released by the hematopoietic cells themselves. Moreover, the studies of Orlofsky and Prystowsky $(14,15)$ have shown that the mitogenic stimulation of hematopoietic cells results in reduced levels of the transcripts coding for $\beta$ chemokine C10. $\beta$ chemokine $\mathrm{ClO}$ is released by hematopoietic cells under conditions of differentiation induction, suggesting that this compound has a direct inhibitory effect on the proliferation of late myeloid progenitor cells. Loss of this protein could result in the failure to commit cells to differentiation, and therefore result in the expansion of the late myeloid cells seen in CML.

The reduced levels of $\beta$ chemokine $\mathrm{C} 10$ mRNA in bcrabl-transduced $32 \mathrm{Dcl} 3$ cells as compared to untransfected controls leads to the hypothesis that a reduction in $\beta$ chemokine $\mathrm{C} 10$ contributes in part to unregulated growth of myeloid progenitor cells in chronic myelogenous leukemia.

Other genes that we have identified as ex- 
pressed differentially in 32D cells versus the 32Dcl3P210bcrabl cells are the ribosomal protein L37a mRNA. This gene was originally identified from a subtraction library generated from the spleens of $\mathrm{C} 57 \mathrm{BL} / 6$ and $\mathrm{HW} 81$ mice. C57BL/6 mice show a 10 - to 15 -fold increased induction of interferon gene expression in response to Newcastle disease virus (NDV) compared with HW81 mice (20). Another hypothesis generated by this work is that the ribosomal protein L37a gene may be involved in the alteration of interferon responsiveness or downstream signaling observed in the 32D cells transfected with bcr-abl. Alternatively, the increase in expression of ribosomal protein L37a may be due to a general increase in protein intranscription by the cells transfected with the bcrabl cDNA (21).

The TCP-1-containing chaperonin (22) was found to exhibit increased expression in 32Dcl3P210bcrabl cells compared to that found in 32Dcl 3 cells. The TCP-1-containing chaperonins are believed to be involved in protein folding. Previous work has shown altered expression of gene products that contain thioredoxin catalytic units that might be involved in a similar manner in CML (23). TCP-1 has also been specifically implicated in the folding of the cytoskeletal proteins actin and tubulin (24).

Clearly, the work reported here represents the first of several necessary steps before definitive conclusions can be drawn between the altered levels of expression of these genes and the progression of CML. The alterations in the genes that we have observed in P210bcrabl-positive and -negative cells could arise from a general effect of bcrabl on the protein synthesis in 32Dcl 3 cells or a specific effect of P2 10 bcrabl on the expression of these genes. Studies of CML cells from patients at different stages of the evolution of CML from chronic-phase to blastic-crisis CML are underway in our laboratory to test whether the same changes we have seen in 32D cells after introduction of bcrabl cDNA are also seen in CML cells.

\section{Acknowledgments}

The editorial assistance of Rosemarie Lauzon is greatly appreciated. The authors also recognize the support of CML P01 CA49639 and support from the Bush Leukemia Research Fund. A.B.D. recognizes the Hull Development Fund, the Anderson Chair for Cancer Treatment and Research at the M.D. Anderson Cancer Center, and the Ensign Professorship of Medicine at the Yale University School of Medicine.

\section{References}

1. Nowell PC, Hungerford DA. (1960) Chromosome studies on normal and leukemic human leukocytes. J. Natl. Cancer Inst. 25: 85-109.

2. Rowley JD. (1973) A new consistent chromosomal abnormality in chronic myelogenous leukemia identified by quinacrine fluorescence and giemsa staining. Nature 243: 290-293.

3. Cortez JE, O'Brien S. (1994) Chronic myelogenous leukemia. Curr. Opin. Oncol. 6: 23-31.

4. Wetzler M, Talpaz M, Estrov Z, Kruzrock R. (1993) CML: mechanisms of disease initiation and progress. Leuk. Lymphoma 11 (Suppl. 1): 47-50.

5. Konopka JB, Watanabe SM, Witte ON. (1984) An alteration of the human c-Abl protein in $\mathrm{K} 562$ leukemia cells unmasks associated tyrosine kinase activity. Cell 37: 1035-1042.

6. Laneuville $P$, Sun G, Timm $M$, Vekemans $M$. (1992) Clonal evolution in a myeloid cell line transformed to interleukin-3 independent growth by retroviral transduction and expression of P210bcrabl. Blood 80: 1788-1797.

7. Liang $P$, Pardee AB. (1992) Differential display of eukaryotic messenger RNA by means of the polymerase chain reaction. Science 257: 967-971.

8. Sager R, Anisowics A, Neveu M, Liang P, Sotiropoulou G. (1993) Identification by differential display of $\alpha 6$ integrin as a potential tumor suppressor gene. FASEB J. 7: 964-970.

9. Liang P, Averboukh L, Zhu W, Parkee AB. (1994) Ras activation of genes: Mob-l as a model. Proc. Natl. Acad. Sci. U.S.A. 91: 12515-12519.

10. Shinoura M, Shamraj OI, Hugenholz $\mathrm{H}$, et al. (1995) Identification and partial sequence of cDNA that is differentially expressed in human brain tumors. Cancer Lett. 889: 215-221.

11. Cohen L, Mohr R, Chen YY, et al. (1997) Transcription activation of a ras-like gene (kir) by oncogenic tyrosine kinases. Proc. Natl. Acad. Sci. U.S.A. 91: 12448-12452.

12. Jung $M$, Kondratyev $A D$, Dritschilo A. (1994) Elongation factor $1 \delta$ is enhanced following exposure to ionizing radiation. Cancer Res. 54: 25412543.

13. Schall TJ, Bacon KB. (1994) Chemokines, leukocyte trafficking, and inflammation. Curr. Opin. Immunol. 6: 865-873.

14. Orlofsky A, Berger MS, Prystowsky MB. (1991) Novel expression pattern of a new member of the MIP-1 family of cytokine-like genes. Cell. Regul. 2: 403-412.

15. Orlofsky A, Lin EY, Prystowsky MB. (1994) Selective induction of the $\beta$ chemokine $\mathrm{C} 10$ by IL- 4 in mouse macrophages. J. Immunol. 152: 5084-5091. 
16. Eaves CJ, Cashman JD, Wolpe SD, Eaves AC. (1993) Unresponsiveness of primitive CML cells to MIP-l $\alpha$, an inhibitor of primitive normal hematopoietic cells. Proc. Natl. Acad. Sci. U.S.A. 90: 1201512019.

17. Nirsimloo N, Gordon MY. (1995) Progenitor cells in the blood and marrow of patients with CML respond differently to mouse MIP-1 $\alpha$. Leuk. Res. 19: 319-323.

18. Chasty RC. (1995) MIP- $1 \alpha$ receptors are present on cells enriched for CD34 expression from patients wih CML. Blood 86: 4270-4277.

19. Bhatia R, McGlave PV, Verfaille CM. (1995) Treatment of marrow stroma with interferon alpha restores normal $\boldsymbol{\beta} 1$ integrin dependent adhesion of CML hematopoietic progenitors: role of MIPl $\alpha$. J. Clin. Invest. 96: 931-939.

20. Hirose K, Hakozaki NM, Nyununoya Y, et al. (1995) Chemokines gene transfection into tumor cells reduced tumorigenicity in nude mice in as- sociation with neutrophilic infiltration. Br. J. Cancer 72: 708-714.

21. Su Y, Raj NB, Au WC, Pitha PM. (1993) Primary sequence of the mouse ribosomal protein L37a. Nucl. Acids Res. 21: 4400.

22. Kubota H, Hynes G, Willison K. (1995) The eight Cct gene Cctq encoding the theta subunit of the cytosolic chaperonin containing TCP-1. Gene 154: 231-236.

23. Johnson E, Henzel W, Deisseroth A. (1992) An isoform of protein disulfide isomerase isolated from chronic myelogenous leukemia cells alters complex formation between nuclear proteins and regulatory regions of interferon-inducible genes. J. Biol. Chem. 267: 14412-14417.

24. Sternlicht H, Farr GW, Sternlicht M, Driscoll JK, Willison K, Yaffe MB. (1993) The t-complex polypeptide 1 complex is a chaperonin for tubulin and actin in vivo. Proc. Natl. Acad. Sci. U.S.A. 90: 9422-9426. 